\title{
Primary Mucinous Adenocarcinoma of Appendix
}

\author{
Banwari Lal Bairwa \\ Department of Surgery, M P Birla Hospital, Chittorgarh, Rajasthan, India.
}

\section{Corresponding Author:}

Dr Banwari Lal Bairwa

Email: drbanwaribairwa@gmail.com

This is an Open Access article distributed under the terms of the Creative Commons Attribution License (creativecommons.org/ licenses/by/3.0).

$\begin{array}{lll}\text { Received } & : & \text { March 31, 2020 } \\ \text { Accepted } & : & \text { June 2, 2020 } \\ \text { Published } & : & \text { June 20, } 2020\end{array}$

\begin{abstract}
Background: Primary mucinous adenocarcinoma of appendix is an extremely rare disease in clinical practice. Here, we report a case of primary mucinous adenocarcinoma in a 60 year old gentleman misdiagnosed as having acute appendicitis. Case Report: A 60 year old man presented with symptoms of pain in right iliac fossa. Ultrasonography of abdomen revealed acute appendicitis. Laparoscopic appendectomy was done and histopathological examination identified a well-differentiated mucinous adenocarcinoma of appendix, tumor cells reaching upto serosal surface. Right hemicolectomy was done as a second stage procedure. Conclusion: As some cases are discovered incidentally, this case emphasizes that histopathological examination of all appendectomy specimens is mandatory.
\end{abstract}

Keywords: Appendiceal Neoplasms, Appendicitis, Appendectomy, Colectomy, Mucinous Adenocarcinoma, Pain.

\section{Introduction}

Primary tumors of appendix are unusual. Primary appendiceal adenocarcinomas (PAAs) are very rare malignant neoplasm accounting for $0.05-0.2 \%$ of all appendectomies and only $6 \%$ of all malignant tumors of appendix [1]. Primary adenocarcinoma of appendix constitutes $<0.5 \%$ of all gastrointestinal neoplasm [2]. Recently these tumors have been classified into 4 groups: mucinous adenocarcinoma, colonic type adenocarcinoma, goblet cell carcinoma, signet ring cell carcinoma [3]. In PAAs colonic type is most common and signet ring type is rare tumor. Appendiceal carcinomas are usually well differentiated mucinous adenocarcinoma which tend to produce pseudomyxoma peritonei and do not show metastatic spread until late in the disease process [4]. We report a rare case of mucinous adenocarcinoma in 60 years old gentleman who was misdiagnosed as having acute appendicitis.

\section{Case Report}

A 60 year old man presented with acute pain in right iliac fossa of 2 days duration, which was associated with low grade fever and nausea. No history of weight loss, loss of appetite or similar complaint in past was elicited. Examination revealed tenderness in right iliac fossa. All routine investigations were within normal limits except mild leukocytosis. Ultrasonography (USG) of abdomen showed inflamed, dilated non-compressible tubular structure in right iliac fossa with possibility of acute appendicitis.

Laparoscopic appendectomy was done. An intra-operative diagnosis of acute appendicitis with appendicular lump was made, appendix was enlarged thickened and inflamed [Fig.1]. Appendicular lump was in "U" shape and adhered in right iliac fossa. No mucinous material was found inside peritoneal cavity. Specimen was 
sent for histopathological examination. On gross examination the appendix was enlarged, soft in consistency and reddish in color. On cut section dilated lumen of appendix was filled with mucus. Histopathology confirmed mucinous adenocarcinoma of appendix as there was invasion of wall by malignant cells forming glands and extracellular mucin [Fig.2]. Right hemicolectomy was done as a second stage procedure.

\section{Discussion}

Primary adenocarcinoma of the appendix (PAA) is an extremely rare disease in clinical practice. Risk factors are not established for development of appendix cancers. There are four major histological variants of appendiceal adenocarcinoma: cystic, colonic, carcinoid, and adenocarcinoid. Carcinoids are the most common type, nearly $90 \%$ of all primary appendiceal tumors while mucinous adenocarcinoma is the second most common type. Primary appendiceal malignancy is diagnosed in $0.9-1.4 \%$ of appendectomy specimens [5].

Most of malignant appendix tumors present with acute appendicitis or palpable abdominal mass and are diagnosed incidentally at histopathological examination of the surgically excised specimens or an incidental finding during exploration for another disease [6]. Appendix malignancies may also be asymptomatic and be found incidentally. When symptoms are present, the disease process is often advanced in symptomatic cases. The mean age at presentation for mucinous type PAA is about 50 years with a male predominance of 4:1 [7]. Most of mucinous type PAAs is well differentiated slowly growing pushing rather than infiltrating margin. Its importance lies in the treatment consideration and tendency to produce condition such as pseudomyxoma peritonei.

Treatment of adenocarcinoma of appendix depends on the stage of the disease. When tumor is confined in the appendix, right hemicolectomy is the treatment of choice. The presence of distant

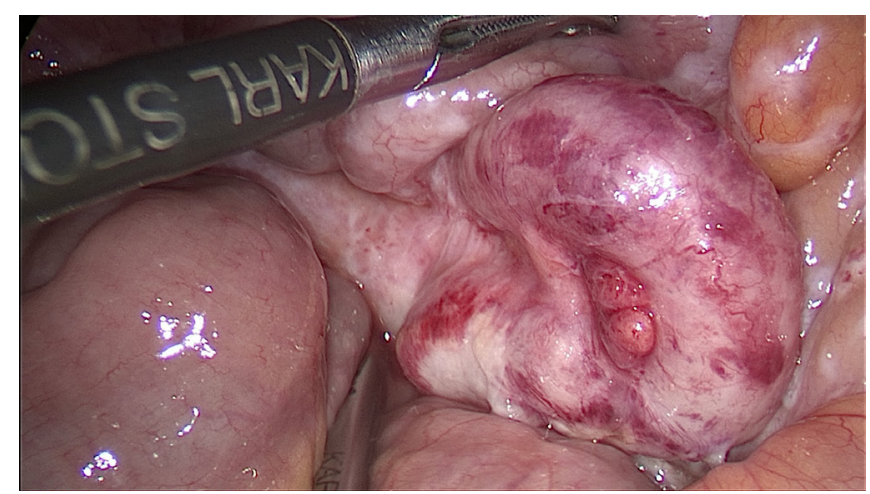

Fig.1: " $U$ " shape inflamed and thickened appendix in right iliac fossa.
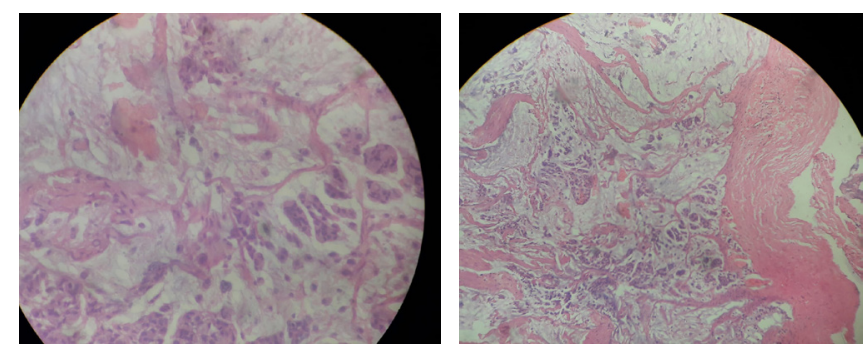

Fig.2: Invasion of appendix wall by malignant cells forming mucinous glands and mucin (H\&E 40).

metastases or peritoneal spread requires aggressive debulking surgery followed with neo-adjuvant and adjuvant chemo-radiotherapy [8]. Therapeutic options for these tumors are: (i) appendectomy for tumor size less than $2 \mathrm{~cm}$, without appendix mesentery infiltration, lymph node involvement and peritoneal seeding; (ii) right hemicolectomy for tumor size more than $2 \mathrm{~cm}$, appendix mesentery infiltration and/or histologically demonstrated lymph node involvement without peritoneal seeding; (iii) complete cytoreduction and hyperthermic intra-peritoneal chemotherapy for any tumor size, appendix mesentery infiltration with peritoneal seeding and lymph node involvement [8].

The prognosis of mucinous adenocarcinoma depends on the stage, grade of malignancy of the mucinous tumor and success of debulking surgery to remove all the tumors that have metastasized into the abdomen. 


\section{Conclusion}

Only few cases of primary mucinous adenocarcinoma of appendix have been reported. Diagnosis of disease is difficult due to lack of specific symptoms and sign. Diagnosis is confirmed by histopathological examination of specimen. Therefore histopathological examination of all appendectomy specimens is mandatory to rule out malignant pathology. This rare tumor was misdiagnosed as acute appendicitis, pre-operatively as well as intra-operatively. Surgical resection with adjuvant chemotherapy is current effective treatment to improve long term survival.

Contributors: BLB performed the surgery, peri-operative patient management, drafted manuscript and approved the final version of this manuscript. He will act as a study guarantor and responsible for all aspects of the study.

Funding: None; Competing interests: None stated.

\section{References}

1. Me O' Donnell, Badger SA, Beattie GC, Carson J, Garstin WI. Malignant neoplasms of the appendix. Int J Colorectal Dis. 2007;22:1239-1248.
2. Ozakyol AH, Saricom T, Kabukceaglu S, Caga T, Erenoglu E. Primary appendiceal adenocarcinoma. Am J Clin Oncol.1999;22:458-459.

3. Mc Cusker ME, Coti TR, Clag LX, Sobin LH. Primary malignant neoplasm of the appendix. Cancer. 2002;94:3307-3312.

4. Ito H, Osteen RT, Bleday R, Zinner MJ, Ashley SW, Whang EE. Appendiceal adenocarcinoma: long-term outcomes after surgical therapy. Dis Colon Rectum. 2004;47:474-480.

5. Connor SJ, Hanna GB, Frizelle FA. Appendiceal tumors: retrospective clinicopathologic analysis of appendiceal tumors from 7,970 appendectomies. Dis Colon Rectum. 1998;41:75-80.

6. Behera PK, Rath PK, Panda R, Satpathi S, Behera R. Primary appendiceal mucinous adenocarcinoma. Indian J Surg. 2011;73:146-148.

7. Conte CC, Petrelli NJ, Stule J, Herrera L, Mittelman A. Adenocarcinoma of the appendix. Surg Gynecol Obstet. 1988;166:451-453.

8. Gonzalez-Moreno S, Sugarbaker PH. Right hemicolectomy does not confer a survival advantage in patients with mucinous carcinoma of the appendix and peritoneal seeding. Br J Surg. 2004;91:304-311. 